\title{
ATRIBUTOS E HABILIDADES DO PROFISSIONAL CONTÁBIL E A IMPORTÂNCIA DE SEUS SERVIÇOS PARA A TOMADA DE DECISÃO EMPRESARIAL
}

\section{ATTRIBUTES AND SKILLS OF THE ACCOUNTING PROFESSIONAL AND THE IMPORTANCE OF ITS SERVICES FOR THE MAKING OF BUSINESS DECISION}

0 artigo foi aprovado e apresentado no VIII Congresso Nacional de Administração e Contabilidade (AdCont), realizado de 19/10 a 21/10 de 2017, no Rio de Janeiro (RJ)

\section{RESUMO}

Esta pesquisa teve como objetivo verificar os atributos e habilidades do profissional contábil e a importância dos serviços prestados por este profissional para a tomada de decisão empresarial. A metodologia deste estudo foi classificada conforme a abordagem como quantitativa, de acordo com os objetivos, como descritiva e quanto aos procedimentos, como pesquisa de levantamento. Como instrumento de coleta de dados, utilizou-se um questionário baseado nos autores Anselmo (2012) e Savi (2013), contendo oito questões fechadas. A população foi de 93 empresas (clientes) de um escritório de contabilidade localizado na cidade de Antônio Carlos, estado de Santa Catarina (SC), e obteve-se uma amostra de 42 respondentes, o que representa $45,16 \%$ da população. Os dados coletados foram tabulados por meio do software Microsoft Excel® e para a análise dos resultados, foram utilizadas as técnicas estatísticas descritiva e univariada, segundo a distribuição de frequência relativa e média, além de teste t para uma amostra e correlação, calculados por meio do software IBM SPSS Statistics 22®. Como principais resultados, foi possível perceber que quanto aos atributos, constatou-se que o profissional contábil deve atender bem e prontamente, zelar pela qualidade dos serviços prestados e antecipar os problemas. No que diz respeito às habilidades, a capacidade de solucionar problemas ganhou destaque. No que diz respeito à importância dos serviços prestados pelo profissional contábil para a tomada de decisão empresarial, todos foram classificados entre importante e muito importante. O serviço que ganhou destaque foi a assessoria para gestão da organização, indicando que as empresas conseguem perceber no profissional contábil a sua importância no sentido de auxiliar na gestão de seus negócios.

Palavras-chave: Profissional Contábil. Atributos. Habilidades. Serviços Contábeis.

\begin{abstract}
This research aimed to verify the attributes and skills of the accounting professional and the importance of the services provided by this professional to the business decision making. The methodology of this study was classified according to the approach as quantitative, according to the objectives, as descriptive and as to the procedures, as survey of survey. As an instrument of data collection, a questionnaire based on the authors Anselmo (2012) and Savi (2013) was used, containing eight closed questions. The population was 93 companies (clients) from an accounting office located in the city of Antonio Carlos, state of Santa Catarina (SC), and a sample of 42 respondents, representing $45.16 \%$ of the population. The data collected were tabulated using Microsoft Excel $\circledR$ software and for the analysis of the results, we used the statistical and univariate statistical techniques, according to the relative and average frequency distribution, as well as t-test for a sample and correlation, calculated using the IBM SPSS Statistics 22® software. As main results, it was possible to perceive that with respect to the attributes, it was verified that the accounting professional must attend well and promptly, watch over the quality of the services rendered and anticipate the problems. In terms of skills, problem-solving skills gained prominence. With regard to the importance of the services provided by the accounting professional for business decision making, all were classified as important and very important. The service that gained prominence was the management advice of the organization, indicating that companies can perceive in the accounting professional its importance in assisting in the management of their business.
\end{abstract}

José Victor Martins

Graduado em Ciências Contábeis pela Universidade do Vale do Itajaí (UNIVALI). Contato: Rua João Coan, 400, Universitário, Biguaçu, SC, CEP: 88.161-064 E-mail: victor.martins@edu.univali.br

\section{Zilton Bartolomeu Martins} Doutorando em Administração pela Universidade do Vale do Itajaí (UNIVALI). Mestre em Administração pela Universidade do Vale do Itajaí (UNIVALI). Especialista em Gerência Contábil, Perícia, Auditoria e Controladoria pela Faculdade Internacional de Curitiba (FACINTER). Graduado em Ciências Contábeis pela Universidade do Vale do Itajaí (UNIVALI). Docente do curso de Ciências Contábeis na Universidade do Vale do Itajaí (UNIVALI). Contato: Rua João Coan, 400, Universitário, Biguaçu, SC, CEP: 88.161-064. E-mail: ziltonmartins@univali.br

Marisa Luciana Schvabe de Morais Doutoranda em Administração pela Universidade do Vale do Itajaí (UNIVALI). Mestra em Engenharia de Produção pela Universidade Federal de Santa Catarina (UFSC). Especialista em Auditoria e Perícia Contábil pela Universidade do Vale do Itajaí (UNIVALI). Graduada em Ciências Contábeis pela Universidade do Vale do Itajaí (UNIVALI). Coordenadora e Docente do curso de Ciências Contábeis na Universidade do Vale do Itajaí (UNIVALI). Contato: Rua João Coan, 400, Universitário, Biguaçu, SC, CEP: 88.161-064. E-mail: marisal@univali.br

Keywords: Accounting Professional. Attributes. Skills. Accounting Services.

Revista Mineira de Contabilidade ISSN 2446-9114 - Periódico Quadrimestral, digital e gratuito. publicado pelo Conselho Regional de Contabilidade. Artigo recebido em 19/02/2018. Pedido de Revisão em 14/05/2018. Aceito em 20/06/2018 por Dra. Rosimeire Pimentel Gonzaga (Editora Adjunta) e Dra. Edvalda Araújo Leal (editora). Publicado em 31/05/2019. Organização responsável pelo periódico: CRCMG. 


\section{INTRODUÇÃO}

O profissional contábil é o principal agente do ambiente que as empresas atuam, o qual está em constante mutação, evoluindo e derrubando fronteiras (FREZATTI; AGUIAR; GUERREIRO, 2007). Ressalta-se que as funções do profissional contábil não se restringem apenas ao âmbito fiscal, mas em um mercado de economia complexa, informações mais precisas para a tomada de decisão, podem ser vitais às empresas (FERREIRA, 2010).

Neste sentido, Silva, Santana e Meirelles Júnior (2017) enfatizam que as exigências profissionais solicitadas ao Contador foram mudando ao longo do tempo, dando origem a um novo perfil profissional, que é representado por aquele que auxilia a empresa no cumprimento de planejamentos previamente estabelecidos, para que assim, a mesma possa alcançar seus objetivos e metas. Miranda e Faria (2016) afirmam ainda que o profissional da área contábil tem se destacado como um elemento primordial, sobretudo na elaboração e controle das informações patrimoniais, de fundamental importância no processo de tomada de decisão.

No que diz respeito aos atributos do profissional contábil, Peleias et al. (2015) afirmam que deve-se possuir iniciativa, liderança, criatividade, autodesenvolvimento, agilidade, flexibilidade, entre outras, para que seja possível este profissional obter e aplicar seus conhecimentos. Em complemento, Brito et al. (2016) apontam como atributos do profissional contábil a contribuição para a sociedade, habilidades de resolução de problemas, entre outros.

Em relação às habilidades, Marin, Lima e Casa Nova (2014) relatam que as habilidades de um profissional contábil consistem na capacidade de manusear os instrumentos e técnicas profissionais, além de domínio de ferramentas tecnológicas relacionadas ao seu trabalho, melhoria no processo de comunicação em geral, necessidade de domínio de vários idiomas, dentre outras. Neste sentido, Oro, Beuren e Carpes (2014) enfatizam que as habilidades gerenciais também são imprescindíveis para que se exerça a profissão de Contador.

Os serviços prestados pelo profissional contábil são importantes no que diz respeito a tomada de decisão empresarial, quando empresas e sociedade usufruem de informações advindas das demonstrações, visando contribuir de maneira positiva para o desempenho econômico das organizações (VALE; FERREIRA; WIESNER, 2016). Desta forma, o serviço contábil se tornou essencial no processo de tomada de decisões para os empreendedores (CUNHA; OLIVIO; MARTINS, 2017).

Neste contexto, motiva-se a fazer a seguinte pergunta de pesquisa: Quais os atributos e habilidades que o profissional contábil deve possuir e a importância dos serviços prestados por este profissional contábil para a tomada de decisão empresarial? Com base neste questionamento, apresenta-se o seguinte objetivo de verificar os atributos e habilidades do profissional contábil e a importância dos serviços prestados por este profissional para a tomada de decisão empresarial.

Como justificativa teórica deste estudo, Cardoso, Riccio e Albuquerque (2009) verificaram a existência de uma estrutura de interdependência subjacente às competências do Contador, explicando-as melhor e sugerem que se avalie as percepções de diferentes setores em relação aos atributos e habilidades do profissional que presta serviços contábeis.

Além disto, Anselmo (2012) avaliou a qualidade dos serviços contábeis prestados às microempresas e empresas de pequeno porte comerciais instaladas no centro da cidade de Biguaçu - Santa Catarina e recomenda que seja verificado a importância dos serviços contábeis prestados a qualquer tipo de empresa, sejam comerciais, industriais ou de serviços.

Por fim, Savi (2013) verificou a percepção da classe contábil sananduvense a respeito dos desafios e das perspectivas que se mostram à profissão na atualidade e propõe novos estudos relacionados ao profissional contábil, acerca de sua representatividade para as organizações e para a sociedade.

Em relação a justificativa empírica, conhecer os atributos e habilidades do profissional contábil pode auxiliar os Contadores em seu desenvolvimento profissional. Além disto, ao perceber a importância dada pelos clientes aos serviços prestados para a tomada de decisão empresarial se pode mensurar a real importância atribuída ao profissional contábil e fazer com que as organizações contábeis possam reavaliar sua atuação no mercado.

Esta pesquisa contém, além desta introdução, o referencial teórico sobre o tema, os procedimentos metodológicos utilizados para a realização da pesquisa, a análise dos resultados e por fim, as considerações finais deste artigo.

\section{REFERENCIAL TEÓRICO}

O referencial teórico do presente estudo é dividido em quatro partes, sendo elas: a origem da profissão contábil, os atributos e habilidades do profissional contábil, os principais serviços prestados pela contabilidade, a importância da profissão contábil para a sociedade e estudos anteriores sobre os temas.

\subsection{Origem da Profissão Contábil}

É difícil mensurar sobre a origem da profissão contábil, porém, existem relatos de desenhos em escavações encontrados dos povos primitivos que tem ligação com a contagem do patrimônio e, apesar de inicialmente rudimentares, serviam como inventários. Com relação a técnica de registro, especificamente, alguns historiadores defendem que os primeiros vestígios, ainda que insipientes, datam de 4.000 a.C. (BORREGO, 2016).

Mas a história da contabilidade como ciência consolidou-se pelo trabalho elaborado pelo Frei Luca Paccioli, que publicou na Itália, em 1494, um tratado sobre Contabilidade dando nascimento a escola italiana de contabilidade e o 
surgimento também das partidas dobradas. A escola italiana dominou o cenário mundial até o início do século XX, porém, com o desenvolvimento da contabilidade nos Estados Unidos, se formou a escola contábil americana, que domina o cenário atual (MARION, 1998).

O Tratactus de Computis et Scripturis (Contabilidade por Partidas Dobradas), obra que contribuiu para inserir a contabilidade entre os ramos do conhecimento humano, enfatizava que a teoria contábil do débito e do crédito correspondia a teoria dos números positivos e negativos (BEZERRA; NEVES; VALADÃO, 2016).

No Brasil, a chegada da Corte Portuguesa em 1808, desencadeou uma série de transformações na sociedade local, que culminaram com a Proclamação da República, em 1822. Segundo Homero Júnior (2017), os primeiros grandes movimentos na profissão contábil no país datam desta mesma época. O autor cita como exemplos a publicação das primeiras obras sobre Contabilidade, a adoção do sistema de partidas dobradas na escrituração governamental, e a criação das primeiras aulas de comércio.

Araújo et al. (2016) reforçam ao afirmar que a chegada da família Real ao Brasil foi determinante no sentido de normatizar as práticas contábeis no Brasil, visto que D. João VI, em 1808, passa a obrigar os Contadores Gerais da Real Fazenda a aplicarem o método das partidas dobradas na escrituração mercantil.

Embora se tenha registros de aulas de comércio na Bahia (em 1813), na Paraíba (em 1830), no Rio de Janeiro (em 1833), em Pernambuco (1837), no Maranhão (1839), em Santa Catarina (1850), no Amazonas (1852) e, em 1858, no Rio Grande do Sul, a primeira escola de contabilidade do Brasil foi a Escola de Comércio do Rio de Janeiro, reconhecida pelo decreto $n^{\circ}$ 1.339/1905 (BRASIL, 1905). Inicialmente, a escola dava ao seu aluno concluinte o diploma de guarda-livros, porém no ano de 1945 foi instituído o Decreto-lei nº 8.191 que mudou a denominação de guarda-livros para Técnico em Contabilidade (SILVA, 2017).

O primeiro curso superior em Ciências Contábeis foi criado pelo Decreto-lei n 7.988 de 22/09/1945 quando surgiu o Contador, efetivamente, como um profissional (BRASIL, 1945). No ano de 1946, o decreto de Lei $n^{\circ} 9.295$, regulamentou a profissão no país, criando o Conselho Federal de Contabilidade e os Conselhos Regionais, definindo as atribuições do Contador e dando outras providências (BRASIL, 1946).

De acordo com Barbosa e Ott (2015), a profissão contábil sempre acompanhou o processo de evolução da sociedade. Portanto, para ter atingido seu estágio atual de regulação profissional, muitos esforços foram despendidos pelos antigos profissionais da contabilidade. Segundo os autores, o Contador deve olhar com orgulho para a denominação Guarda Livros, pois todo o prestigio e a importância da sua profissão advém desse antigo profissional que, ainda segundo os autores, não teve muito prestígio.

\subsection{Atributos e Habilidades do Profissional Contábil}

O símbolo representativo do profissional contábil é o caduceu, um brasão formado um cajado entrelaçado com duas serpentes e que na sua parte superior tem duas pequenas asas. Souza e Gaertner (2016) indicam que dos itens que compõem o caduceu, o bastão expressa o poder, as duas serpentes representam sabedoria (que se deve ter em trabalhar e proteger as riquezas das pessoas que depositam sua confiança no profissional), as asas representam a diligência e o elmo é emblemático de pensamentos elevados.

Segundo Ribeiro (2015), o caduceu significava para os romanos "o equilíbrio moral e da boa conduta". Pode-se perceber então, que além dos atributos relacionados ao caduceu, há também uma relevante importância nas questões relacionadas a ética, na formação acadêmica do profissional de Ciências Contábeis.

Na verdade, muitos são os atributos e habilidades necessárias para o bom desempenho das funções de um profissional da Contabilidade. Barp, Fortes e Sonaglio (2014) ressaltam que o bom Contador deve ter conhecimentos, habilidades, ser crítico e competente. Ressalta-se que Ott et al. (2012) já afirmavam que o Contador desenvolve habilidades visando o seu sucesso profissional.

Para Silva (2014), habilidade é "saber fazer". Está, portanto, relacionado à prática aplicada das competências adquiridas. $\mathrm{O}$ autor destaca ainda que as habilidades são consideradas essenciais nas ações do indivíduo, demandando domínio de conhecimentos e de competências adquiridas.

Lemes e Miranda (2014) salientam que, cada vez mais, as organizações passam a exigir dos profissionais que militam na área contábil, conhecimentos que ultrapassem as questões técnicas. Destacam que o perfil desejado deve ser condizente com a dinâmica atual das organizações, o que significa ter habilidades diferenciadas que possibilitem que estes profissionais participem, de forma consistente, das decisões da empresa.

Segundo o estudo de Fleury e Fleury (2001), o profissional das organizações deve saber agir, saber o que e porque faz; saber julgar escolher e decidir; saber mobilizar recursos, criar sinergia, desenvolver competências; saber se comunicar, compreender, trabalhar, transmitir informações e conhecimentos; saber aprender, trabalhar o conhecimento e a experiência e rever modelos mentais, ou seja, saber desenvolver-se; saber engajar-se e se comprometer; saber empreender, assumir riscos e se comprometer; saber assumir responsabilidades; ser responsável ao assumir os riscos e consequências de seus atos e sendo por isso reconhecido e; ter visão estratégica, conhecer e entender o negócio da organização que é seu ambiente, identificando oportunidades e alternativas.

Nunes et al. (2014) apresentam em seu estudo um conjunto de habilidades que devem ser adquiridas, consolidadas e desenvolvidas pelos profissionais da contabilidade, dividindo-as em cinco grandes grupos: habilidades intelectuais 
(que auxiliam na identificação e solução de problemas, na análise crítica e na tomada de decisões); habilidades técnicas e funcionais (que são aquelas específicas e gerais relacionadas a contabilidade em si); habilidades pessoais (relacionadas às atitudes e comportamentos); habilidades interpessoais e de comunicação (que possibilitam a interação do profissional da contabilidade com outras áreas do conhecimento) e; habilidades organizacionais e de gerenciamento de negócios (relacionadas ao funcionamento das empresas).

O Contador além de exercer a tradicional prática relacionada à escrituração contábil, pode exercer sua profissão, de acordo com o artigo $2^{\circ}$ da Resolução $C F C n^{\circ} 560 / 1983$, que trata das prerrogativas da profissão estabelecidas pelo artigo 25 da Resolução supracitada, como: perito contábil, auditor, fiscal, gestor de empresas, gestor público, atuarial, consultor e professor (CONSELHO FEDERAL DE CONTABILIDADE, 1983). Diante de tantas opções de atuação, frente a tantas obrigações e constantes mudanças na legislação o profissional da contabilidade, o Contador, necessita então, possuir o maior número de atributos e habilidades para exercer sua profissão de maneira que atenda às necessidades de seus clientes. Ressalta-se que as Instituições de Ensino Superior (IES) necessitam estabelecer a organização curricular para os cursos de Ciências Contábeis por meio do Projeto Pedagógico, com a descrição do perfil profissional para o formando, em termos de competências e habilidades (CONSELHO NACIONAL DE EDUCAÇÃO, 2004).

De acordo com os resultados obtidos na pesquisa de Pires, Ott e Damacena (2009), para atender as expectativas do mercado de trabalho e se manter competitivo, o Contador deve, além de dominar a técnica contábil, desenvolver e aprimorar também as competências que transcendem os conhecimentos tradicionalmente relacionados à contabilidade societária e fiscal, inclusive para atuar no nível operacional. Portanto, segundo Lemes e Miranda (2014), a responsabilidade de formação do profissional não pode ser embasada somente na academia. Tendo em vista que o profissional contábil deve possuir um número vasto de habilidades e atributos, que são carregados de responsabilidades, sua capacitação deve ir além de sua formação acadêmica. Para o profissional manter-se competitivo necessita de atualização contínua realizando seu ofício de maneira a atender a demanda dos seus clientes, e intermediando suas relações com o fisco.

\subsection{Principais Serviços Prestados pela Contabilidade}

A profissão contábil foi regulamentada pelo Decreto-lei $n^{\circ} 9.295 / 1946$ e, posteriormente alterada pela Lei $n^{\circ}$ 12.249/2010, que considera como trabalhos técnicos e específicos de contabilidade: a organização e execução de serviços de contabilidade em geral; a escrituração dos livros de contabilidade obrigatórios, bem como de todos os necessários no conjunto da organização contábil e levantamento dos respectivos balanços e demonstrações, e; a realização de perícias judiciais ou extrajudiciais, revisão de balanços e de contas em geral, verificação de haveres revisão permanente ou periódica de escritas, regulações judiciais ou extrajudiciais de avarias grossas ou comuns, assistência aos Conselhos Fiscais das sociedades anônimas e quaisquer outras atribuições de que são de natureza técnica conferidas aos profissionais de contabilidade (BRASIL, 1946; BRASIL, 2010).

De um modo geral, a contabilidade tem por função a prestação de serviços, fornecendo informações relacionadas ao patrimônio das organizações e auxiliando no processo de tomada de decisões, com vistas, justamente, a proteção destes patrimônios (VALE; FERREIRA; WIESNER, 2016). Entretanto, não há possibilidade de se falar em serviços e não mencionar a palavra qualidade, uma vez que é ela quem determina não só quanto o cliente está disposto a pagar por tal serviço, como também a forma como este serviço é prestado (CUNHA; OLIVIO; MARTINS, 2017).

Carvalho e Tomaz (2010) relatam que para uma prestação de serviço com qualidade é necessário que sejam atendidos alguns requisitos, dentre eles: cumprir os prazos estabelecidos pelos entes Federal, Estadual e Municipal; atender as normas fiscais e tributárias; executar os serviços em tempo hábil e com segurança; e, manter um total controle na parte gerencial das organizações. Soma-se a estes aspectos, certamente, atender todas as normativas que norteiam a atividade profissional.

Segundo Cordeiro e Duarte (2006), não se tolera que a contabilidade esteja sendo preparada para uso exclusivo dos mesmos usuários de quatro décadas atrás, tendo em vista que os mercados econômicos, se encontram em um contexto diferenciado. O papel dos profissionais da contabilidade neste novo contexto, envolve a geração de informações que possam proporcionar aos seus usuários conforto no planejamento de suas operações e na gestão dos seus negócios.

Moreira et al. (2009) corroboram ao enfatizar que as organizações estão em constantes modificações e precisam, cada vez mais, de controles e de informações sobre seu negócio. Portanto, não mais caberia aos profissionais da contabilidade servir tão somente como fonte de informações de ordem tributária, mas também, e especialmente, como um apoio a gestão (seja no planejamento, na execução ou no controle).

Outro aspecto importante que deve ser observado no que tange a prestação de serviços contábeis se refere a forte influência e/ou importância das tecnologias da informação nas rotinas que estão sob a responsabilidade dos profissionais da contabilidade. Zwirtes e Alves (2014) destacam o incremento que estas tecnologias exercem, em especial, na velocidade com que se pode realizar tais rotinas, aliada à precisão no processamento dos dados. A implementação de novas tecnologias nas organizações contábeis, vêm dinamizando os serviços prestados.

Silva Júnior e Ávila (2014) ressaltam que a contabilidade deve buscar acompanhar as mudanças tecnológicas reestruturando seus procedimentos e técnicas, de maneira que possam impactar na forma como os serviços são prestados e na forma como a informação chega aos clientes. 


\subsection{Importância da Profissão Contábil para a Sociedade}

A evolução da sociedade tem uma forte ligação com a contabilidade. Catelli e Santos (2001) atestam que é possível verificar que o grau de avanço da contabilidade está diretamente ligado com o progresso econômico, social e institucional de cada sociedade. Neste sentido, Castro (2012) evidencia que as Instituições de Ensino Superior (IES) necessitam preparar profissionais com condições de inserção no mercado de trabalho, aptos a contribuir para o desenvolvimento social.

Bet (2011) complementa salientando que em virtude do desenvolvimento da economia, ocorreu também o avanço da ciência contábil e, para dar suporte as necessidades do mercado, surgiram diferentes instituições que ofereciam cursos de pós-graduação em contabilidade. Este aprofundamento da formação dos profissionais, possibilitado pelos cursos de pós-graduação, contribuiria para melhor atender as demandas da sociedade.

Szuster (2015) também destaca que a contabilidade sempre impulsionou o desenvolvimento da sociedade por meio do controle das operações econômicas e da geração de informações, viabilizando as organizações e possibilitando a mediação entre os diferentes interesses. $O$ autor enfatiza que a atuação da contabilidade no campo empresarial, entidades governamentais e nas entidades sem fins lucrativos está fundamentada na representação fidedigna das informações destas, para os diversos usuários das informações.

Para Merlo e Pertuzatti (2005) entre a sociedade, a empresa e o Estado, o profissional contábil intermedia estas relações, se tornando o elo entre Fisco e contribuinte. Além disto, os autores destacam que a conscientização tributária do profissional contábil pode representar um ponto de partida para a formação cidadã, que é uma das formas mais eficazes de atender as demandas sociais com o patrimônio público.

No âmbito da auditoria, Almeida (2004) menciona que esta pode ser cada vez mais interveniente no diagnóstico de determinadas situações, a fim de evitar fraudes e atos ilegais. Na esfera pública, por exemplo, se poderá, por meio da auditoria, evitar alguma forma de fraude, podendo então, utilizar e aplicar um recurso - não fraudado - para o bem social.

Analisando sob um outro o ponto de vista, também as empresas auditadas e demais usuários das informações contábeis, se beneficiam na medida em que a auditoria possivelmente aumentará o grau de confiabilidade nas informações fornecidas (MORAIS; MARTINS; ALBERTON, 2017).

O profissional contábil, atendendo todas as normativas relacionadas a sua profissão, estará realizando um trabalho relevante para a sociedade, pois o Contador é o principal responsável pela prestação de contas, controle patrimonial, controle fiscal e tributário, setor previdenciário e trabalhista entre outras funções que envolvem obrigações legais, gerenciais e operacionais dos seus clientes.

\subsection{Estudos Anteriores sobre os Temas}

O Quadro 1 a seguir evidencia estudos que abordaram os temas atributos e habilidades do profissional contábil, assim como os serviços contábeis utilizados para a tomada de decisão empresarial.

Quadro 1: Estudos anteriores sobre o tema

\begin{tabular}{|c|c|c|}
\hline Autores & Objetivos & Principais Resultados \\
\hline $\begin{array}{l}\text { Cardoso, Ric- } \\
\text { cio e Albuquer- } \\
\text { que (2009) }\end{array}$ & $\begin{array}{l}\text { Verificar a existência de uma estru- } \\
\text { tura de interdependência subjacen- } \\
\text { te às competências do Contador, } \\
\text { explicando-as melhor. }\end{array}$ & $\begin{array}{l}\text { A partir da proposta das } 18 \text { variáveis coletadas na lite- } \\
\text { ratura, submetidas à avaliação dos } 159 \text { respondentes, } \\
\text { chegou-se a } 13 \text { variáveis organizadas em quatro fatores: } \\
\text { competência específica, competência de conduta e admi- } \\
\text { nistração, competência de técnicas de gestão e competên- } \\
\text { cia de articulação. Estes fatores podem dar respostas ao } \\
\text { grande questionamento deste estudo, que é a existência } \\
\text { de uma estrutura comum. }\end{array}$ \\
\hline $\begin{array}{c}\text { Ott et al. } \\
(2011)\end{array}$ & $\begin{array}{l}\text { Comparar a percepção de estudan- } \\
\text { tes de cursos de Ciências Contábeis } \\
\text { em Instituições de Ensino Superior } \\
\text { (IES) brasileiras e profissionais } \\
\text { da contabilidade no Brasil quanto } \\
\text { aos conhecimentos, habilidades e } \\
\text { métodos de ensino-aprendizagem } \\
\text { considerados como mais importan- } \\
\text { tes para a atuação do Contador no } \\
\text { mercado de trabalho. }\end{array}$ & $\begin{array}{l}\text { Os resultados evidenciaram maiores níveis de importân- } \\
\text { cia percebida pelos profissionais (quando comparados } \\
\text { aos estudantes) nos quesitos investigados. Compara- } \\
\text { tivamente com a China e com os EUA, os escores dos } \\
\text { profissionais brasileiros são sempre maiores para as três } \\
\text { dimensões (conhecimentos, habilidades e métodos). Os } \\
\text { estudantes brasileiros em comparação com os chineses, } \\
\text { de forma geral, também atribuem maior importância para } \\
\text { as três dimensões analisadas. }\end{array}$ \\
\hline
\end{tabular}




\begin{tabular}{|c|c|c|}
\hline Autores & Objetivos & Principais Resultados \\
\hline $\begin{array}{l}\text { Anselmo } \\
\text { (2012) }\end{array}$ & $\begin{array}{l}\text { Avaliar a qualidade dos serviços } \\
\text { contábeis prestados às microem- } \\
\text { presas e empresas de pequeno porte } \\
\text { comerciais instaladas no centro da } \\
\text { cidade de Biguaçu - Santa Catari- } \\
\text { na. }\end{array}$ & $\begin{array}{l}\text { Foi possível verificar que nem todos os escritórios de } \\
\text { contabilidade estão atendendo e auxiliando seus clientes } \\
\text { de maneira satisfatória. Observou-se, também, que uma } \\
\text { grande parte das empresas, mesmo recebendo relatórios } \\
\text { periodicamente, pouco fazem uso deles como base para } \\
\text { tomada de decisão, muitos empresários acham que os } \\
\text { Contadores servem somente para fins legais e os valores } \\
\text { cobrados pelos serviços, um pouco caro. }\end{array}$ \\
\hline Castro (2012) & $\begin{array}{l}\text { Identificar o que pensam os alunos } \\
\text { do curso de Ciências Contábeis da } \\
\text { Universidade Federal de Santa Ca- } \\
\text { tarina sobre as competências e ati- } \\
\text { vidades da profissão de Contador. }\end{array}$ & $\begin{array}{l}\text { Há uma lacuna entre as competências importantes para o } \\
\text { Contador e o seu domínio pelos acadêmicos formandos, } \\
\text { além de existir uma insatisfação quanto à prática contábil } \\
\text { proporcionada no curso. }\end{array}$ \\
\hline Savi (2013) & $\begin{array}{l}\text { Verificar a percepção da classe con- } \\
\text { tábil sananduvense a respeito dos } \\
\text { desafios e das perspectivas que se } \\
\text { mostram à profissão na atualidade. }\end{array}$ & $\begin{array}{l}\text { A contabilidade está em permanente evolução, acompa- } \\
\text { nhando as transformações sociais e econômicas, e assu- } \\
\text { mindo uma função gerencial e não apenas de apuração } \\
\text { e mensuração de resultados. Evidenciou-se também, que } \\
\text { cabe ao profissional além da formação específica, com- } \\
\text { petências e atributos obedecendo princípios, normas e } \\
\text { diretrizes éticas fundamentais da área contábil. }\end{array}$ \\
\hline $\begin{array}{l}\text { Oro, Beuren e } \\
\text { Carpes (2014) }\end{array}$ & $\begin{array}{l}\text { Analisar a aderência entre as com- } \\
\text { petências e habilidades requeridas } \\
\text { pelo mercado nacional na contrata- } \\
\text { ção do profissional de controladoria } \\
\text { e a proposição para sua formação } \\
\text { acadêmica na percepção de docen- } \\
\text { tes da disciplina de controladoria. }\end{array}$ & $\begin{array}{l}\text { Os resultados da pesquisa relacionam as competências } \\
\text { e habilidades requeridas pelo mercado nacional na con- } \\
\text { tratação do profissional de controladoria e a proposição } \\
\text { para sua formação acadêmica na percepção de docentes } \\
\text { da disciplina de controladoria. Com base na pesquisa rea- } \\
\text { lizada, conclui-se que existe certa aderência entre o perfil } \\
\text { desejado pelo mercado de trabalho e a proposição para a } \\
\text { formação acadêmica do controller. }\end{array}$ \\
\hline $\begin{array}{l}\text { Lemes e Mi- } \\
\text { randa (2014) }\end{array}$ & $\begin{array}{l}\text { Verificar o grau de importância que } \\
\text { os profissionais da contabilidade } \\
\text { atuantes no Triângulo Mineiro atri- } \\
\text { buem às habilidades preconizadas } \\
\text { pela IES } 3 \text { - International Educa- } \\
\text { tion Standards } 3 \text { - da IFAC - Inter- } \\
\text { national Federation of Accountan- } \\
\text { ts. }\end{array}$ & $\begin{array}{l}\text { Foram verificados altos percentuais de concordância dos } \\
\text { profissionais em relação aos itens pesquisados (IES 3). } \\
\text { Também pode ser constatado por meio da análise fatorial } \\
\text { que os quatro fatores gerados agruparam itens de forma } \\
\text { semelhante àquela preconizada pela IFAC, apontando } \\
\text { aderência da IES } 3 \text { à realidade dos profissionais da amos- } \\
\text { tra. }\end{array}$ \\
\hline $\begin{array}{l}\text { Peleias et al. } \\
\text { (2015) }\end{array}$ & $\begin{array}{l}\text { Relatar resultados de uma investi- } \\
\text { gação realizada por meio da técnica } \\
\text { da história oral, relativos à identifi- } \\
\text { cação e análise de atributos valori- } \\
\text { zados no desempenho da profissão } \\
\text { por empresários contábeis da gran- } \\
\text { de São Paulo. }\end{array}$ & $\begin{array}{l}\text { Os dados obtidos revelaram atributos e perfis comuns ne- } \\
\text { cessários ao desempenho da profissão entre os entrevista- } \\
\text { dos e as organizações contábeis que dirigem, tais como: } \\
\text { iniciaram as organizações de forma simples, em um am- } \\
\text { biente familiar; as organizações são estruturadas de for- } \\
\text { ma departamentalizada delegando poderes; declararam } \\
\text { ter atingido destaque no segmento da profissão contábil } \\
\text { com muito trabalho, dedicação e persistência; executam } \\
\text { suas atividades pautadas na ética, honestidade e serieda- } \\
\text { de; procuram novos desafios e empreendimentos e pos- } \\
\text { suem como meta a valorização da profissão contábil. }\end{array}$ \\
\hline $\begin{array}{l}\text { Brito et al. } \\
\quad(2016)\end{array}$ & $\begin{array}{l}\text { Conhecer a percepção de graduan- } \\
\text { dos em Contabilidade, Contadores } \\
\text { e da sociedade, acerca dos atributos } \\
\text { da profissão de contabilidade. }\end{array}$ & $\begin{array}{l}\text { Foram notados indícios que possibilitam concluir que } \\
\text { as maiores distorções de percepção encontram-se nos } \\
\text { atributos "Satisfação no trabalho", "Estabilidade no } \\
\text { emprego" e"Nível ético", sendo que os graduandos apre- } \\
\text { sentaram as menores médias nos três atributos. }\end{array}$ \\
\hline
\end{tabular}




\begin{tabular}{|c|c|c|}
\hline Autores & Objetivos & Principais Resultados \\
\hline $\begin{array}{l}\text { Cunha, Oli- } \\
\text { vio e Martins } \\
\text { (2017) }\end{array}$ & $\begin{array}{l}\text { Descrever a percepção dos empre- } \\
\text { sários acerca do grau de importân- } \\
\text { cia e nível de satisfação dos servi- } \\
\text { ços prestados pelo profissional da } \\
\text { contabilidade. }\end{array}$ & $\begin{array}{l}\text { Os clientes atribuem maior importância para a apuração } \\
\text { de impostos e confecção de folha de pagamento. Já os } \\
\text { serviços de assessoria para a gestão da empresa e geração } \\
\text { dos demonstrativos contábeis são considerados de me- } \\
\text { nor importância. Com relação ao nível de satisfação, os } \\
\text { clientes estão entre "satisfeitos" e "muito satisfeitos" em } \\
\text { relação à maior parte dos serviços prestados pelos profis- } \\
\text { sionais da contabilidade. }\end{array}$ \\
\hline
\end{tabular}

Fonte: Elaborado pelos Autores (2018)

A partir do Quadro 1, percebe-se que pesquisas relacionadas a atributos e habilidades do profissional contábil apresentam uma variedade em relação ao objeto de pesquisa, podendo-se observar, com base no arcabouço teórico, alunos, Contadores e também, profissionais de outras áreas. No que diz respeito aos serviços contábeis, os estudos permeiam entre grau de importância e nível de satisfação dos usuários de tais serviços.

\section{PROCEDIMENTOS METODOLÓGICOS}

A presente pesquisa classifica-se quanto a abordagem como quantitativa, de acordo com os objetivos, como descritiva e quanto aos procedimentos, como pesquisa de levantamento.

O estudo foi realizado com empresas (clientes) de um escritório de contabilidade localizado na cidade de Antônio Carlos, estado de Santa Catarina (SC). A escolha do escritório em questão se deu por conta de ser o maior escritório da cidade. Sendo assim, a população deste estudo foi de 93 empresas (clientes do escritório), resultando na amostra de 42 questionários que foram respondidos em tempo hábil, representando $45,16 \%$ da população pesquisada.

O instrumento de coleta de dados utilizado neste estudo, foi um questionário baseado nos autores Anselmo (2012) e Savi (2013), contendo oito questões fechadas e validado por três professores da área. Desta forma, os questionários foram enviados via e-mail, por um funcionário do escritório de contabilidade, para as empresas participantes desta pesquisa. É importante ressaltar que este e-mail foi enviado três vezes (uma vez a cada semana para as empresas que ainda não tivessem respondido ao instrumento) e que caso o responsável por alguma empresa (que também não tivesse respondido o questionário) comparecesse ao escritório, o instrumento era impresso e respondido por este representante. $\mathrm{O}$ período de coleta de dados ocorreu durante o mês de abril de 2016.

Os dados coletados foram tabulados por meio do software Microsoft Excel® e foram utilizadas as técnicas estatísticas descritiva e univariada, segundo a distribuição de frequência relativa e média, além de teste t para uma amostra e correlação, calculados por meio do software IBM SPSS Statistics 22®.

Para análise do teste t para uma amostra, levou-se em consideração o nível de significância de 0,05 para formulação das hipóteses de nulidade e alternativa. Assim, a hipótese de nulidade é que as médias são iguais (grau de significância maior que 0,05 ) e a hipótese alternativa é que as médias são diferentes (grau de significância menor que 0,05).

Para análise da força de associação do coeficiente de correlação, utilizou-se como base o que tratam Hair Júnior et al. (2005), conforme os valores que constam no Quadro 2.

Quadro 2: Força de associação do coeficiente de correlação

\begin{tabular}{|c|c|}
\hline Variação do coeficiente* & Força de associação \\
$0,91-1,00$ & Muito forte \\
$0,71-0,90$ & Alta \\
$0,41-0,70$ & Moderada \\
$0,21-0,40$ & Pequena, mas definida \\
$0,01-0,20$ & Leve, quase imperceptível \\
* Supõe que o coeficiente de correlação seja & \\
estatisticamente significativo. & \\
\hline
\end{tabular}

Fonte: Adaptado de Hair Júnior. et al. (2005)

Desta forma, para que fossem definidas as relações entre as variáveis, levou-se em consideração, assim como no teste t para uma amostra, o percentual de $5 \%$, para que o coeficiente de correlação seja estatisticamente significativo. 


\section{ANÁLISE DOS RESULTADOS}

A análise dos resultados foi dividida em três grupos de respostas, sendo que o primeiro representa o perfil das empresas que compõem a amostra deste estudo, o segundo trata dos atributos e habilidades do profissional contábil e o terceiro trata da importância dos serviços prestados por este profissional para a tomada de decisão empresarial.

No primeiro grupo de resultados, a Tabela 01 apresenta informações em relação ao perfil das empresas pesquisadas classificando-as por município em que estão instaladas.

Tabela 01: Município que a empresa se situa

\begin{tabular}{cc} 
Município & Frequência Relativa \\
\hline Antônio Carlos (SC) & $69 \%$ \\
Biguaçu (SC) & $19 \%$ \\
São Pedro de Alcântara (SC) & $12 \%$ \\
\hline
\end{tabular}

Fonte: Dados da Pesquisa (2018)

A Tabela 01 demonstra que todas as empresas pesquisadas são do estado de Santa Catarina, sendo que a maioria delas (correspondendo a um índice de 69\%) estão localizadas no município de Antônio Carlos, ou seja, o escritório contábil possui em sua maioria clientes da própria cidade onde está situado. Os demais clientes (em menor proporção) estão situados nos municípios vizinhos, Biguaçu e São Pedro de Alcântara. A Tabela 02 apresenta o porte das empresas pesquisadas em relação ao seu faturamento anual.

Tabela 02: Porte das empresas pesquisadas

\begin{tabular}{cc} 
Porte das Empresas & Frequência Relativa \\
\hline Microempreendedor Individual & $15 \%$ \\
Microempresa & $54 \%$ \\
Empresa de Pequeno Porte & $31 \%$ \\
\hline
\end{tabular}

Fonte: Dados da Pesquisa (2018)

Na Tabela 02 vê-se que a maioria das empresas pesquisadas (54\%) possuem o porte de microempresas. O motivo de não haver clientes de grande porte na pesquisa pode ser justificado pelo fato destas empresas normalmente disporem de serviços contábeis realizados internamente, ou seja, sem a necessidade de terceirização. Na Tabela 03 evidencia-se o tempo de atuação no ramo das empresas pesquisadas.

Tabela 03: Tempo de atuação no ramo

\begin{tabular}{cc} 
Tempo de Atuação & Frequência Relativa \\
\hline Menos de 1 ano & $4 \%$ \\
Entre 1 a 3 anos & $27 \%$ \\
Entre 3 a 6 anos & $50 \%$ \\
Entre 6 a 9 anos & $15 \%$ \\
10 anos ou mais & $4 \%$ \\
\hline
\end{tabular}

Fonte: Dados da Pesquisa (2018)

De acordo com a Tabela 03, metade das empresas pesquisadas atuam no ramo entre 3 e 6 anos, o que indica que os clientes do escritório em questão já possuem certa experiência no mercado. Ressalta-se o pequeno número de novos empreendimentos na região, visto que somente $4 \%$ das empresas respondentes possuem menos de 1 ano de funcionamento. A Tabela 04 apresenta o tempo em que a empresa é cliente do mesmo escritório de contabilidade. 
Tabela 04: Tempo em que é cliente do mesmo escritório de contabilidade

\begin{tabular}{cc}
\hline Tempo no mesmo escritório de contabilidade & Frequência Relativa \\
\hline Menos de 1 ano & $8 \%$ \\
Entre 1 a 3 anos & $27 \%$ \\
Entre 3 a 6 anos & $50 \%$ \\
Entre 6 a 9 anos & $12 \%$ \\
10 anos ou mais & $3 \%$ \\
\hline
\end{tabular}

Fonte: Dados da Pesquisa (2018)

Nota-se na Tabela 04 que quase a totalidade das empresas respondentes (96\%) são clientes do mesmo escritório de contabilidade desde o seu nascimento. Em um comparativo com o tempo de atuação (Tabela 03), somente 4\% das empresas mudaram de escritório contábil recentemente (menos de 1 ano), sendo que $3 \%$ destas empresas já atuam no mercado entre 6 e 9 anos e $1 \%$ atua no período de 10 anos ou mais. Sendo assim, se pode depreender que as empresas somente buscam outros profissionais contábeis para atender suas demandas a fim de encontrar melhores opções do que as que as ofertadas pela contabilidade atual, após o período de 6 anos de funcionamento.

O segundo grupo de resultados trata dos atributos e habilidades do profissional contábil. Inicialmente, por meio da Tabela 05, buscou-se compreender a visão dos respondentes acerca da profissão contábil.

Tabela 05: Profissão contábil na visão dos clientes

\begin{tabular}{cc}
\hline Profissão contábil na visão dos clientes & Frequência Relativa \\
\hline Como mais uma profissão & $4 \%$ \\
Em expansão e reconhecimento & $15 \%$ \\
Igualam-se as outras profissões & $27 \%$ \\
Profissão promissora & $50 \%$ \\
Profissão saturada no mercado & $4 \%$ \\
\hline
\end{tabular}

Fonte: Dados da Pesquisa (2018)

A Tabela 05 indica que os respondentes possuem uma visão positiva acerca da profissão contábil, visto que metade da amostra a considera uma profissão promissora, somado ao fato de 15\% considerarem uma profissão em expansão e reconhecimento. Desta forma, percebe-se o reconhecimento por mais da metade dos respondentes (65\%) no que diz respeito a importância da profissão contábil. Este resultado corrobora com o encontrado por Savi (2013), no qual 48\% consideraram a profissão como promissora e 42\% afirmaram que a profissão está em fase de expansão e reconhecimento. Pode-se observar na Tabela 06, os atributos do profissional contábil de acordo com seus clientes.

Tabela 06: Atributos do profissional contábil.

\begin{tabular}{cc} 
Atributos & Frequência Relativa \\
\hline Antecipar os problemas & $30 \%$ \\
Atender bem e prontamente & $35 \%$ \\
Zelar pela qualidade dos serviços prestados & $35 \%$
\end{tabular}

Fonte: Dados da Pesquisa (2018)

A partir dos resultados apresentados na Tabela 06, percebe-se um resultado dividido, já que para os clientes pesquisados, os atributos do profissional contábil "atender bem e prontamente" (35\%), "zelar pela qualidade dos serviços prestados" (35\%) e "antecipar os problemas" (30\%), obtiveram índices bastante próximos, revelando um grau de importância similar. Ressalta-se que as opções de atributos "ser acessível" o "outros" não foram escolhidos por nenhuma empresa, não sendo evidenciados na Tabela acima.

Estes resultados demonstram que o profissional contábil além de ficar atento as rotinas pertinentes a legislação contábil, fiscal e trabalhista, também deve preocupar-se com as necessidades de seus clientes. Estes achados diferem dos encontrados por Savi (2013), que totalizaram 48\% para zelar pela qualidade dos serviços prestados, $42 \%$ para antecipação dos problemas e somente $5 \%$ para atender bem e prontamente. Esta diferença pode ter se dado devido a amostras distintas, pois enquanto Savi (2013) fez um estudo com profissionais contábeis, esta pesquisa possui como objeto, os clientes de um escritório de contabilidade. 
Por meio da Tabela 07, pode-se observar as habilidades que o profissional contábil deve possuir para exercer seu ofício, segundo seus clientes.

Tabela 07: Habilidades do profissional contábil

\begin{tabular}{cc}
\hline Habilidades & Frequência Relativa \\
\hline Motivação & $4 \%$ \\
Postura proativa & $4 \%$ \\
Domínio da tecnologia & $4 \%$ \\
Capacidade de solucionar problemas & $73 \%$ \\
Rapidez no aprendizado & $15 \%$ \\
\hline
\end{tabular}

Fonte: Dados da Pesquisa (2018)

A Tabela 07 evidencia que a grande maioria dos respondentes (73\%) acreditam que a maior habilidade do profissional contábil é a capacidade de solucionar problemas. Neste ponto, talvez se possa inferir que esta habilidade obteve um alto índice pelo fato da amostra desta pesquisa ser composta somente por empresas de pequeno porte, o que pode demonstrar falta de planejamento por parte dos mesmos. Além disto, as opções “criatividade" e "outras" também não foram escolhidas por nenhuma empresa respondente. Desta forma, não foram evidenciadas na Tabela acima.

Este resultado discorda de Savi (2013), quando somente 32\% de seus respondentes apontaram a opção "capacidade de solucionar problemas". Ressalta-se que a frequência das outras opções foram 31\% para "postura proativa”, 21\% para "rapidez no aprendizado" e 16\% para "domínio da tecnologia".

O último grupo de respostas para análise foi o que trata da importância dos serviços prestados por este profissional para a tomada de decisão empresarial. Os serviços foram avaliados em uma escala do tipo likert de 4 pontos, sendo 1 para "sem importância", 2 para "pouco importante", 3 para "importante" e 4 para "muito importante", conforme foi utilizado na pesquisa de Anselmo (2012) e posteriormente no estudo de Cunha, Olivio e Martins (2017). Sendo assim, a Tabela 08 apresenta o grau de importância dos serviços contábeis para a tomada de decisão empresarial.

Tabela 08: Grau de importância dos serviços contábeis para a tomada de decisão empresarial

\begin{tabular}{ccc}
\hline Serviços Prestados & Média & Teste t para uma amostra \\
\hline Abertura e baixa de empresas & 3,19 & 0,000 \\
Preenchimento de Guias Fiscais & 3,35 & 0,000 \\
Confecção de Folha de Pagamento & 3,58 & 0,000 \\
Geração de demonstrativos contábeis & 3,27 & 0,000 \\
Elaboração de Registros e Livros & 3,54 & 0,000 \\
Assessoria para gestão da empresa & 3,65 & 0,000 \\
Entrega de declarações para o Fisco & 3,31 & 0,000 \\
\hline
\end{tabular}

Nota: Significância ao nível de 0,05 (2 extremidades).

Fonte: Elaborado pelos Autores (2018)

Conforme a Tabela 08, verificou-se que os respondentes classificaram todos os serviços entre importantes e muito importantes para a tomada de decisão empresarial, com resultados bastante próximos, que variaram entre 3,19 e 3,65. Estas médias revelam uma valorização por parte dos clientes acerca dos serviços que são prestados pelo profissional contábil.

A maior média foi atribuída a "assessoria para gestão da empresa”, com 3,65. É interessante observar que isto pode indicar que os respondentes já conseguem perceber no profissional contábil a sua importância no sentido de auxiliar na gestão de seus negócios. Entretanto, é preocupante que o item "geração de demonstrativos contábeis" tenha obtido a segunda pior média, com 3,27. Embora o serviço tenha sido classificado como importante de maneira geral, esta média pode indicar que os demonstrativos contábeis podem não estar sendo usados adequadamente no que tange a tomada de decisão empresarial.

Estes resultados discordam dos achados de Anselmo (2012), que concluiu que o serviço prestado pelo profissional contábil com menor importância para a tomada de decisão empresarial foi a "assessoria para gestão da empresa", enquanto o serviço que recebeu maior representatividade foi "confecção de folha de pagamento".

Da mesma forma, os achados deste estudo também são distintos quando comparados aos resultados obtidos por 
Cunha, Olivio e Martins (2017), quando o serviço com mais destaque foi "apuração de impostos”, com média 3,66, enquanto o serviço com menor média foi “assessoria na gestão da empresa”, com 2,79.

Além disto, convém destacar que todas as médias dos serviços evidenciados na Tabela 08 são estatisticamente diferentes, uma vez que o teste t para uma amostra apresentou valores de 0,000 para todos os serviços (sendo menores que 0,05 e, assim, rejeitando a hipótese de nulidade), ou seja, cada um destes serviços possui uma importância distinta para a tomada de decisão empresarial. Este resultado corrobora com a pesquisa de Cunha, Olivio e Martins (2017), quando enfatizam que os gestores possuem uma visão otimista sobre os serviços prestados pela contabilidade, mostrando que são importantes para a sua gestão.

Neste sentido, a Tabela 09 demonstra a correlação dos serviços contábeis para a tomada de decisão empresarial.

Tabela 09: Correlação dos serviços contábeis para a tomada de decisão empresarial

\begin{tabular}{|c|c|c|c|c|c|c|c|}
\hline Correlação & 1 & 2 & 3 & 4 & 5 & 6 & 7 \\
\hline $\begin{array}{l}\text { 1) Abertura e Baixa de } \\
\text { Empresas }\end{array}$ & 1 & $\begin{array}{c}0,670^{* *} \\
0,000\end{array}$ & $\begin{array}{c}0,498^{\star *} \\
0,001\end{array}$ & $\begin{array}{c}0,678^{\star *} \\
0,000\end{array}$ & $\begin{array}{c}0,612^{\star \star} \\
0,000\end{array}$ & $\begin{array}{c}0,372^{*} \\
0,015\end{array}$ & $\begin{array}{c}0,698^{\star *} \\
0,000\end{array}$ \\
\hline $\begin{array}{l}\text { 2) Preenchimento de Guias } \\
\text { Fiscais }\end{array}$ & $\begin{array}{c}0,670^{\star *} \\
0,000\end{array}$ & 1 & $\begin{array}{c}0,863^{* *} \\
0,000\end{array}$ & $\begin{array}{c}0,869^{\star *} \\
0,000\end{array}$ & $\begin{array}{c}0,882^{\star *} \\
0,000\end{array}$ & $\begin{array}{c}0,773 \text { ** } \\
0,000\end{array}$ & $\begin{array}{c}0,892^{\star \star} \\
0,000\end{array}$ \\
\hline $\begin{array}{l}\text { 3) Confecção de Folha de } \\
\text { Pagamento }\end{array}$ & $\begin{array}{c}0,498^{* *} \\
0,001\end{array}$ & $\begin{array}{c}0,863^{\star \star} \\
0,000\end{array}$ & 1 & $\begin{array}{c}0,838^{\star *} \\
0,000\end{array}$ & $\begin{array}{c}0,882^{\star *} \\
0,000\end{array}$ & $\begin{array}{c}0,869^{\star \star} \\
0,000\end{array}$ & $\begin{array}{c}0,839^{\star *} \\
0,000\end{array}$ \\
\hline $\begin{array}{l}\text { 4) Geração de demonstrativos } \\
\text { contábeis }\end{array}$ & $\begin{array}{c}0,678^{\star *} \\
0,000\end{array}$ & $\begin{array}{c}0,869 * * \\
0,000\end{array}$ & $\begin{array}{c}0,838^{\star *} \\
0,000\end{array}$ & 1 & $\begin{array}{c}0,854^{\star \star} \\
0,000\end{array}$ & $\begin{array}{c}0,829^{\star *} \\
0,000\end{array}$ & $\begin{array}{c}0,968^{\star \star} \\
0,000\end{array}$ \\
\hline $\begin{array}{l}\text { 5) Elaboração de Registros e } \\
\text { Livros }\end{array}$ & $\begin{array}{c}0,612^{\star *} \\
0,000\end{array}$ & $\begin{array}{c}0,882^{\star *} \\
0,000\end{array}$ & $\begin{array}{c}0,882^{\star *} \\
0,000\end{array}$ & $\begin{array}{c}0,854^{\star \star} \\
0,000\end{array}$ & 1 & $\begin{array}{c}0,808^{\star *} \\
0,000\end{array}$ & $\begin{array}{c}0,850^{\star *} \\
0,000\end{array}$ \\
\hline $\begin{array}{l}\text { 6) Assessoria para gestão da } \\
\text { empresa }\end{array}$ & $\begin{array}{c}0,372^{\star} \\
0,015\end{array}$ & $\begin{array}{c}0,773^{* *} \\
0,000\end{array}$ & $\begin{array}{c}0,869 * * \\
0,000\end{array}$ & $\begin{array}{c}0,829 * * \\
0,000\end{array}$ & $\begin{array}{c}0,808^{* *} \\
0,000\end{array}$ & 1 & $\begin{array}{c}0,793^{\star *} \\
0,000\end{array}$ \\
\hline $\begin{array}{l}\text { 7) Entrega de declarações } \\
\text { para o Fisco }\end{array}$ & $\begin{array}{c}0,698^{* *} \\
0,000\end{array}$ & $\begin{array}{c}0,892^{\star *} \\
0,000\end{array}$ & $\begin{array}{c}0,839 \star * \\
0,000\end{array}$ & $\begin{array}{c}0,968^{\star *} \\
0,000\end{array}$ & $\begin{array}{c}0,850 * * \\
0,000\end{array}$ & $\begin{array}{c}0,793 * * \\
0,000\end{array}$ & 1 \\
\hline
\end{tabular}

** A correlação é significativa ao nível 0,01 (2 extremidades)

* A correlação é significativa ao nível de 0,05 (2 extremidades)

Fonte: Elaborado pelos Autores (2018)

A partir dos dados apresentados na Tabela 09, percebe-se que todos os serviços prestados pelo profissional contábil estão relacionados (seja em maior ou menor grau). Ressalta-se que a maior correlação acontece entre "entrega de declarações para o fisco" e "geração de demonstrativos contábeis", com 0,968 (muito forte), enquanto a menor correlação foi entre "assessoria para gestão da empresa" e "abertura e baixa de empresas", com 0,372 (força pequena, mas definida). Convém ressaltar que a força da correlação entre a grande maioria dos serviços é classificada como alta, ou seja, varia entre 0,71 e 0,90 (HAIR JÚNIOR et al., 2005).

Neste contexto, estas relações corroboram com o que afirma Castro (2012), que qualquer empresa necessita, por força de lei, da prestação de serviços de um Contador, evidenciando um mercado de trabalho amplo para esta profissão. Além disto, Cunha, Olivio e Martins (2017) enfatizam que os serviços prestados pela contabilidade auxiliam na geração de informações para a tomada de decisão.

\section{CONSIDERAÇÕES FINAIS}

O presente artigo teve como objetivo verificar os atributos e habilidades do profissional contábil e a importância dos serviços prestados por este profissional para a tomada de decisão empresarial. Os respondentes são otimistas quanto a profissão contábil, por considerarem a mesma como uma profissão promissora e em expansão e reconhecimento.

Quanto aos atributos, foi possível constatar que o profissional contábil deve atender bem e prontamente, zelar pela qualidade dos serviços prestados e antecipar os problemas. No que diz respeito as habilidades, a capacidade de solucionar problemas ganhou destaque.

Já os serviços prestados pelo profissional contábil e a sua importância para a tomada de decisão empresarial, todos foram classificados entre importantes e muito importantes. O serviço que ganhou destaque foi a assessoria para gestão da empresa, indicando que as organizações conseguem perceber no profissional contábil a sua importância no sentido de auxiliar na gestão de seus negócios. 
Entretanto, se faz necessário apontar que todas as médias dos serviços prestados pelo profissional contábil são estatisticamente diferentes, ou seja, cada um destes possui um nível de importância diferente quando se fala em tomada de decisão empresarial. Além disto, percebe-se que todos estes serviços estão relacionados, em maior ou menor grau, entre si.

Neste contexto, foi possível concluir que os profissionais contábeis devem ficar atentos no que diz respeito a seus atributos e habilidades para prestarem serviços de qualidade, visto a importância dos mesmos para a tomada de decisão.

O principal limitador da presente pesquisa foi a falta de empresas de grande porte como clientes do escritório objeto do estudo, visto que, os resultados obtidos poderiam ter sofrido alterações. Além disto, uma amostra maior poderia apresentar resultados distintos.

Como sugestão para novos estudos, sugere-se que a presente pesquisa seja replicada em outros escritórios de contabilidade, localizados em Santa Catarina ou em outros estados do país. Também recomenda-se que na amostra de novas pesquisas, constem empresas de grande porte e não somente microempresas, empresas de pequeno porte e microempreendedores individuais, além de testes estatísticos mais específicos, como análise fatorial ou análise de regressão.

\section{REFERÊNCIAS}

ALMEIDA, B. J. M. Auditoria e sociedade: o diálogo necessário. Revista Contabilidade \& Finanças, v. 15, n. 34, p. 80-96, 2004.

ANSELMO, T. A. Avaliação da qualidade dos serviços contábeis prestados às micro e pequenas empresas comerciais com sede no bairro Centro em Biguaçu/SC. 2012. 76f. Trabalho de Conclusão de Curso (Graduação em Ciências Contábeis) Universidade Federal de Santa Catarina, Florianópolis, 2012.

ARAÚJO, M. R. et al. Lei n 6.404/76: Uma análise dos principais avanços proporcionados à Contabilidade no Brasil. Revista de Gestão e Contabilidade da UFPI, v. 2, n. 2, p. 17-32, 2016.

BARBOSA, M. A. G.; OTT, E. A organização profissional contábil no estado do Rio Grande do Sul no período de 1882 a 1947. Contabilidade Vista \& Revista, v. 24, n. 4, p. 34-50, 2015.

BARP, A. D.; FORTES, M. M. S.; SONAGLIO, D. Implementation Public Digital Bookkeeping System - Sped: Changes in Everyday Perception of Accounting Professionals. In: INTERNATIONAL CONFERENCE ON INFORMATION SYSTEMS AND TECHNOLOGY MANAGEMENT - CONTECSI, 11, 2014, São Paulo/SP. Anais... São Paulo: USP, 2014.

BET, S. M. A percepção dos alunos do curso de Ciências Contábeis da UNESC no que tange a graduação e a profissão contábil. 2011. 62f. Trabalho de Conclusão de Curso (Graduação em Ciências Contábeis) - Universidade do Extremo Sul Catarinense, Criciúma, 2011.

BEZERRA, M. E. N.; NEVES, R. M.; VALADÃO, R. S. International Accounting Standard (IAS) 38 e os bens intangíveis. Revista Interatividade, v. 4, n. 2, p. 90-109, 2016.

BORREGO, A. C. Origem histórica da relação entre a tributação e a Contabilidade: Revisão de Literatura. In: ENCUENTRO AECA, 17, 2016, Bragança/Portugal. Anais... Bragança: Instituto Politécnico de Bragança, 2016.

BRASIL. Decreto $n^{\circ}$ 1.339, de 09 de janeiro de 1905. Declara Instituições de utilidade pública a Academia de Comércio do Rio de Janeiro, reconhece os diplomas por ela conferidos, como de caráter oficial e dá outras providências. Disponível em: http://legislacao.planalto.gov.br/legisla/legislacao.nsf/b2394d7e1ab9a970032569b9004e148d/c8677591f23edc25032569fa006a92f3?OpenDocument. Acesso em: 29 mai. 2018.

BRASIL. Decreto-lei $n^{\circ} 7.988$, de 22 de setembro de 1945. Dispõe sobre o ensino superior de ciências econômicas e de ciências contábeis e atuariais. Disponível em: http://www.lexml.gov.br/urn/urn:lex:br:federal:decreto.lei:1945-09-22;7988. Acesso em: 10 jun. 2016.

BRASIL. Decreto-lei n 9.295, de 27 de maio de 1946. Cria o Conselho Federal de Contabilidade, define as atribuições do Contador e do Técnico em Contabilidade, e dá outras providências. Disponível em: http://www.planalto.gov.br/ccivil_03/ decreto-lei/Del9295.htm. Acesso em: 10 jun. 2016.

BRASIL. Lei $\mathrm{n}^{\circ} 12.249$, de 11 de junho de 2010. Altera as Leis nos 8.248 , de 23 de outubro de 1991, 8.387, de 30 de dezembro de 1991, 11.196, de 21 de novembro de 2005, 10.865, de 30 de abril de 2004, 11.484, de 31 de maio de 2007, 11.488, de 15 de junho de 2007, 9.718, de 27 de novembro de 1998, 9.430, de 27 de dezembro de 1996, 11.948, de 16 de junho de 2009, 11.977, de 7 de julho de 2009, 11.326, de 24 de julho de 2006, 11.941, de 27 de maio de 2009, 5.615, de 13 de outubro de 1970, 9.126, de 10 de novembro de 1995, 11.110, de 25 de abril de 2005, 7.940, de 20 de dezembro de 1989, 9.469, de 10 de julho de 1997, 12.029, de 15 de setembro de 2009, 12.189, de 12 de janeiro de 2010, 11.442, de 5 de janeiro de 2007, 11.775, de 17 de setembro de 2008 , os Decretos-Leis nos 9.295, de 27 de maio de 1946, 1.040, de 21 de outubro de 1969, e a Medida Provisória no 2.158-35, de 24 de agosto de 2001; revoga as Leis nos 7.944, de 20 de dezembro de 1989, 10.829, de 23 de dezembro de 2003, o Decreto-Lei no 423, de 21 de janeiro de 1969; revoga dispositivos das Leis nos 8.003, de 14 de março de 1990, 8.981, de 20 de janeiro de 1995, 5.025, de 10 de junho de 1966, 6.704, de 26 de outubro de 1979, 9.503, de 23 de setembro de 1997; e dá outras providências. Disponível em: http://www.planalto.gov.br/ccivil_03/_ato2007-2010/2010/lei/l12249.htm. Acesso em: 10 jun. 2016.

BRITO, J. D. F. et al. A percepção da profissão contábil sob a ótica de três públicos: alunos, contabilistas e profissionais ligados à outras áreas. Revista de Contabilidade da UFBA, v. 10, n. 1, p. 36-52, 2016.

CARDOSO, R. L.; RICCIO, E. L.; ALBUQUERQUE, L. G. Competências do Contador: Um estudo sobre a existência de uma estrutura de interdependência. Revista de Administração, v. 44, n. 4, art. 5, p. 365-379, 2009.

CARVALHO, J. R. M.; TOMAZ, F. A. S. Qualidade em serviços contábeis: um estudo nas empresas do setor de comércio varejista de material de construção. Revista Alcance, v. 17, n. 2, p. 192-204, 2010. 
CASTRO, C. C. T. As competências do Contador sob a perspectiva dos alunos formandos do curso de Ciências Contábeis da UFSC. 2012. 68f. Trabalho de Conclusão de Curso (Graduação em Ciências Contábeis) - Universidade Federal de Santa Catarina, Florianópolis, 2012.

CATELLI, A.; SANTOS, E. S. Internet: desafio para uma contabilidade interativa. Revista Contabilidade \& Finanças, v. 12, n. 25 , p. $24-41,2001$

CONSELHO FEDERAL DE CONTABILIDADE. Resolução CFC 560 de 28 de outubro de 1983. Dispõe sobre as prerrogativas profissionais de que trata o artigo 25 do Decreto-lei $\mathbf{n}^{\circ}$ 9.295, de 27 de maio de 1946. Disponível em: cfc.org.br/sisweb/sre/ docs/RES_560.doc. Acesso em: 10 jun. 2016.

CONSELHO NACIONAL DE EDUCAÇÃO. Resolução CNE/CES 10, de 16 de dezembro de 2004. Institui as Diretrizes Curriculares Nacionais para o curso de graduação em Ciências Contábeis, bacharelado, e dá outras providências. Disponível em: http://portal.mec.gov.br/cne/arquivos/pdf/rces10_04.pdf. Acesso em: 29 mai. 2018.

CORDEIRO, J. S.; DUARTE, A. M. P. O profissional contábil diante da nova realidade. Qualit@s Revista Eletrônica, v. 5, n. 6, p. 68-96, 2006.

CUNHA, A.; OLIVIO, A. C.; MARTINS, Z. B. Percepção de clientes acerca do grau de importância e nível de satisfação com os serviços prestados pelo profissional da contabilidade. Revista Brasileira de Contabilidade, v. 1, n. 227, p. 70-81, 2017.

FERREIRA, M. B. Os efeitos da tecnologia da informação na Contabilidade. Revista contábil \& Empresarial, v. 1, n. 1, p. 1-17, 2010.

FLEURY, M. T. L.; FLEURY, A. Construindo o conceito de competência. Revista de administração contemporânea, v. 5, n. especial, p. 183-196, 2001.

FREZATTI, F; AGUIAR, A. B.; GUERREIRO, R. Diferenciações entre a Contabilidade financeira e a Contabilidade gerencial: uma pesquisa empírica a partir de pesquisadores de vários países. Revista de Contabilidade e Finanças, v. 18, n. 44, p. 9-22, 2007.

HAIR JÚNIOR, J. F. et al. Fundamentos de Métodos de Pesquisa em Administração. Porto Alegre: Bookman, 2005.

HOMERO JÚNIOR, P. F. A constituição do campo científico e a baixa diversidade da pesquisa contábil brasileira. Revista de Educação e Pesquisa em Contabilidade (REPeC), v. 11, n. 3, p. 314-328, 2017.

LEMES, D. F.; MIRANDA, G. J. Habilidades profissionais do Contador preconizadas pela IFAC: um estudo com profissionais da região do Triângulo Mineiro. Advances in Scientific and Applied Accounting, v. 7, n. 2, p. 293-316, 2014.

MARIN, T. I. S.; LIMA, S. J.; CASA NOVA, S. P. C. Formação do Contador: O que o mercado quer, é o que ele tem? Um estudo sobre o perfil profissional dos alunos de Ciências Contábeis da FEA-USP. Revista Contabilidade Vista \& Revista, v. 25, n. 2, p. 59-83, 2014.

MARION, J. C. Contabilidade empresarial: 8.ed. São Paulo: Atlas, 1998

MERLO, R. A., \& PERTUZATTI, E. Cidadania e responsabilidade social do contador como agente da conscientização tributária das empresas e da sociedade. In: CONGRESSO USP, 5, 2005, São Paulo/SP. Anais... São Paulo: USP, 2005.

MIRANDA, V. L.; FARIA, J. A. Caricaturas e estereótipos do Contador: Como a imagem do profissional de contabilidade vem sendo veiculada em um jornal de grande circulação no Brasil?. Revista de Administração, Contabilidade e Economia (RACE), v. 15, n. 3, p. 1087-1116, 2016.

MORAIS, M. L. S.; MARTINS, Z. B.; ALBERTON, L. Percepção dos Auditores Independentes quanto à efetividade da Capacitação realizada para o Cumprimento da Norma Brasileira de Contabilidade de Educação Profissional Continuada. Pensar Contábil, v. 19, n. 69, p. 4-17, 2017.

MOREIRA, R. et al. Qualidade da prestação de serviços contábeis sob a ótica dos clientes. Revista Catarinense da Ciência Contábil, v. 8, n. 23, p. 23-41, 2009.

NUNES, I. V. et al. A percepção dos estudantes de ensino médio sobre as responsabilidades de um Contador. Revista Universo Contábil, v. 10, n. 4, p. 144-161, 2014.

ORO, I. M.; BEUREN, I. M.; CARPES, A. M. S. Competências e habilidades exigidas do Controller e a proposição para sua formação acadêmica. Contabilidade Vista \& Revista, v. 24, n. 1, p. 15-36, 2013.

OTT, E. et al. Relevância dos conhecimentos, habilidades e métodos instrucionais na perspectiva de estudantes e profissionais da área contábil: Estudo comparativo internacional. Revista Contabilidade \& Finanças - USP, v. 22, n. 57, p. 338-356, 2011.

PELEIAS, I. R. et al. Atributos do desempenho profissional na visão de empresários Contábeis da grande São Paulo. Revista de Educação e Pesquisa em Contabilidade (REPeC), v. 9, n. 2, p. 160-181, 2015.

PIRES, C. B.; OTT, E.; DAMACENA, C. “Guarda-Livros” ou "Parceiros de Negócios”? Uma análise do perfil profissional requerido pelo mercado de trabalho para Contadores na Região Metropolitana de Porto Alegre (RMPA). Contabilidade Vista \& Revista, v. 20, n. 3, p. 157-187, 2009.

RIBEIRO, M. Porque Contadores Precisam Estudar Psicologia. Revista Pensar Contábil, v. 4, n. 1, p.14, p. 2015.

SAVI, E. A percepção da classe contábil de Sananduva sobre os desafios e perspectivas da profissão. 2013. 60f. Trabalho de Conclusão de Curso (Graduação em Ciências Contábeis) - Universidade de Passo Fundo, Passo Fundo, 2013.

SILVA, R. A. C. História da escola brasileira de Contabilidade até o surgimento da primeira doutrina contábil positiva. Revista Contaduria Universidad de Antioquia, v. 1, n. 68, p. 313-332, 2017.

SILVA, B. N.; SANTANA, C. L.; MEIRELLES JÚNIOR, J. C. Formação acadêmica em Ciências Contábeis e sua relação com o mercado de trabalho: A percepção de formandos de Ciências Contábeis de uma Instituição de Ensino Superior. Revista Brasileira de Contabilidade, v. 1, n. 225, p. 66-77, 2017. 
SILVA, O. L. Avaliação das habilidades conceituais, procedimentais e atitudinais: Estudo no Exame de Suficiência em Contabilidade 2012-2013. 2014. 118f. Dissertação (Mestrado em Contabilidade) - Programa de Pós-Graduação em Contabilidade, Universidade Federal do Paraná, Curitiba, 2014.

SILVA JÚNIOR, M.; ÁVILA, L. A. C. Estudo das relações entre sistemas integrados de informações e a prestação de serviços de escritório de Contabilidade em uma cidade de Minas Gerais. In: Congresso USP - Controladoria e Contabilidade, 14, 2014, São Paulo/ SP. Anais... São Paulo: USP, 2014.

SOUZA, W. J. T.; GAERTNER, C. A. Os símbolos da Contabilidade. Negócios, v. 1, n. 14, p. 106-115, 2016.

SZUSTER, N. Temos do que nos orgulhar na Contabilidade brasileira. Revista Contabilidade \& Finanças, v. 26, n. 68, p. 121125,2015

VALE, L. R.; FERREIRA, F. M.; WIESNER, R. A aplicação prática do código de ética na prestação de serviços contábeis. Revista Brasileira de Contabilidade, v. 1, n. 221, p. 16-29, 2016.

ZWIRTES, A.; ALVES, T. W. Os impactos causados pela inovação tecnológica em escritórios de Contabilidade do Rio Grande do Sul: uma Análise Fatorial. Revista de Educação e Pesquisa em Contabilidade (REPeC), v. 8, n. 1, p. 39-53, 2014. 